\title{
Management and outcome of infants and children with right atrial isomerism
}

Masood Sadiq, Oliver Stümper, Joseph V De Giovanni, John G C Wright, Babulal Sethia, William J Brawn, Eric D Silove

\begin{abstract}
Objectives-To assess the current results and outcome of surgery in infants and children with right atrial isomerism and complex congenital heart disease. Setting-Tertiary referral centre.

Methods-20 consecutive children with right atrial isomerism and complex congenital heart disease underwent surgery over a 6 year period between August 1987 and July 1993. The results and outcome were analysed according to age, presentation, and surgical procedures.
\end{abstract}

Results-Patients were divided into two groups depending on age at presentation and initial surgery: group $A$ comprised 11 patients who required surgical intervention in the first month of life (mean age 5 days); and group $B$ comprised nine patients who required initial surgical intervention after the first month of life (mean age 6.8 months). Seven (64\%) of the 11 patients in group $A$ had obstructed pulmonary venous drainage and ten (91\%) had pulmonary atresia. There were seven early deaths (64\%), including the five patients who required systemic to pulmonary artery shunt and simultaneous repair of obstructed pulmonary veins. The long-term survival rate in this group was $18 \%$ (two of 11 ). Pulmonary venous obstruction was present in two $(22 \%)$ of the nine patients in group $B$ and four (44\%) had pulmonary atresia. There were no early deaths. One patient died after a second palliative procedure. There was one late sudden death. Four patients had a Fontan operation with no deaths. Two of the remaining three patients meet the Fontan criteria. The long-term survival rate in this group was $78 \%$ (seven of nine). Conclusions-Surgical management of patients with right atrial isomerism who have complex congenital heart disease carries a high mortality and remains palliative. The overall survival rate was $45 \%$ (nine of 20); $18 \%$ in patients requiring surgery in the first month of life (group A) and $78 \%$ in patients requiring surgery after the first month of life (group B) (P< $0.001)$. Of the total of 20 patients, nine were potential candidates for a Fontan operation. Seven of these have undergone a Fontan procedure with five survivors.

(Heart 1996;75:314-319)

Keywords: right atrial isomerism in infants; surgical management and outcome; congenital heart disease; surgical results for right atrial isomerism

Right atrial isomerism is associated with complex congenital heart disease. The characteristic spectrum of significant cardiac lesions includes anomalous pulmonary venous drainage which is often obstructed, a common atrium, complete atrioventricular septal defect, ventriculoarterial discordance, and severe pulmonary outflow tract obstruction or atresia. Other associated lesions are visceral heterotaxia, asplenia, and congenital malformations mainly involving the genitourinary and gastrointestinal system. ${ }^{1-3}$ The prevalence of atrial isomerism (both right and left) in the New England regional infant cardiac program has been reported to be $4 \%$ of all infants with congenital heart malformations. ${ }^{4}$ The prevalence of right atrial isomerism compared with that of left atrial isomerism is higher in necropsy series $^{3}$ than in surgical series. ${ }^{5}$ This is related, in part, to the increased severity and complexity of congenital heart disease in right atrial isomerism and in part, to the increased risk of sepsis in the absence of a functioning spleen. ${ }^{6}$ The natural history of patients with right atrial isomerism and complex congenital heart disease is death of more than one third of untreated patients within the first week of life. One year survival was only $21 \%$ in the necropsy series reported by Rose et al. ${ }^{3}$ Cardiac failure and anoxia were the predominant causes of death $(54 \%)$, followed by surgery $(20 \%)$ and infection (10\%).

Previous studies have documented poor surgical results in infants and children with right atrial isomerism and complex congenital heart disease. ${ }^{578}$ When considering the recent advances in surgical results in the treatment of infants and children with other forms of complex congenital heart disease ${ }^{9}$ one might also expect improved results in children with right atrial isomerism. Some 20 consecutive infants with right atrial isomerism who presented to 
Patient data

\begin{tabular}{|c|c|c|c|c|}
\hline $\begin{array}{l}\text { Patient } \\
\text { no }\end{array}$ & $\begin{array}{l}\text { Age at } \\
\text { surgery }\end{array}$ & Morphological features & Palliation & Outcome \\
\hline \multicolumn{5}{|c|}{ Group A (surgery under the age of 1 month) } \\
\hline 1 & 9 days & $\begin{array}{l}\text { CA,cAVSD,TGA, } \\
\text { PAt, disconnected PAs }\end{array}$ & $\begin{array}{l}\text { SPS, and } \\
\text { repair of PAs }\end{array}$ & Hospital death \\
\hline 2 & 2 days & $\begin{array}{l}\text { OPVD (infracardiac), } \\
\text { CAVSD,TGA, PAt }\end{array}$ & $\begin{array}{l}\text { SPS } \\
\text { plus OPVD repair }\end{array}$ & Hospital death \\
\hline 3 & 1 day & $\begin{array}{l}\text { Dextrocardia, OPVD (supracardiac) } \\
\text { CA,cAVSD,TGA, PAt }\end{array}$ & $\begin{array}{l}\text { SPS } \\
\text { plus OPVD repair }\end{array}$ & Hospital death \\
\hline 4 & 2 weeks & $\begin{array}{l}\text { OPVD (infracardiac),cAVSD, } \\
\text { CA,TGA, PAt }\end{array}$ & $\begin{array}{l}\text { SPS } \\
\text { OPVD repair ( } 1 \text { month) }\end{array}$ & $\begin{array}{l}\text { Late death; Fontan } \\
\text { performed at the age of } \\
2 \cdot 5 \text { years; take down } \\
\text { and central shunt }\end{array}$ \\
\hline 5 & 7 days & $\begin{array}{l}\text { Mixed TAPVC,CA, } \\
\text { cAVSD,DILV,TGA, PAt }\end{array}$ & SPS & $\begin{array}{l}\text { Survivor; } \\
\text { Fontan performed at the } \\
\text { age of } 5 \text { years }\end{array}$ \\
\hline 6 & 1 day & $\begin{array}{l}\text { OPVD (supracardiac), cAVSD, } \\
\text { TGA, PAt }\end{array}$ & $\begin{array}{l}\text { SPS } \\
\text { plus OPVD repair }\end{array}$ & Hospital death \\
\hline 7 & 6 days & $\begin{array}{l}\text { OPVD (infracardiac), cAVSD, } \\
\text { CA,TGA,DORV, PAt }\end{array}$ & $\begin{array}{l}\text { SPS } \\
\text { plus OPVD repair }\end{array}$ & Hospital death \\
\hline 8 & 8 days & CA,cAVSD,DORV, PAt & SPS & $\begin{array}{l}\text { Hospital death after } \\
\text { BV repair ( } 3 \text { weeks) }\end{array}$ \\
\hline 9 & 3 days & $\begin{array}{l}\text { OPVD (supracardiac),cAVSD, } \\
\text { TGA,DORV, PAt }\end{array}$ & $\begin{array}{l}\text { SPS } \\
\text { plus OPVD repair }\end{array}$ & Hospital death \\
\hline 10 & 2 days & $\begin{array}{l}\text { Partial OPVD (supracardiac), } \\
\text { cAVSD,TGA,DORV,PSt }\end{array}$ & OPVD repair & $\begin{array}{l}\text { Survivor, redo } \\
\text { veins, SPS }\end{array}$ \\
\hline 11 & 3 days & $\begin{array}{l}\text { Dextrocardia, supracardiac TAPVC, } \\
\text { CA,cAVSD,TGA,PAt,PDA }\end{array}$ & SPS & $\begin{array}{l}\text { Second SPS; Fontan } \\
\text { performed at the age } \\
\text { of } 4 \text { years; late hospital } \\
\text { death }\end{array}$ \\
\hline \multicolumn{5}{|c|}{ Group B (surgery after the age of 1 month) } \\
\hline 12 & 5 weeks & $\begin{array}{l}\text { Partial OPVD (supracardiac), } \\
\text { cAVSD,DIRV,DORV,PSt }\end{array}$ & SPS & $\begin{array}{l}\text { Late hospital death; } \\
\text { OPVD and PA repair }\end{array}$ \\
\hline 13 & 2 years & cAVSD,TGA,PSt,hypoplastic RV & CP shunt & $\begin{array}{l}\text { Survivor, Fontan } \\
\text { performed at age of } \\
2 \text { years }\end{array}$ \\
\hline 14 & 3 months & $\begin{array}{l}\text { CA,cardiac TAPBV, } \\
\text { cAVSD,TGA,DORV,PSt }\end{array}$ & SPS & $\begin{array}{l}\text { Survivor CP shunt } \\
\text { plus TAPVC }\end{array}$ \\
\hline 15 & 4 months & $\begin{array}{l}\text { Dextrocardia, supracardiac TAPVC, } \\
\text { cAVSD,TGA,PSt }\end{array}$ & $\begin{array}{l}\text { TAPVC repair } \\
\text { plus CP shunt }\end{array}$ & $\begin{array}{l}\text { Survivor; } \\
\text { Fontan performed at } \\
\text { the age of } 2.8 \text { years }\end{array}$ \\
\hline 16 & 8 months & $\begin{array}{l}\text { DIRV,DORV,cAVSD,PSt (valve } \\
\text { plus subvalve),PDA }\end{array}$ & CP shunts & Survivor \\
\hline 17 & 1 year & $\begin{array}{l}\text { Dextrocardia,CA,cAVSD,TGA, } \\
\text { PAt, MAPCAS }\end{array}$ & $\begin{array}{l}\text { SPS plus ligation } \\
\text { of MAPCAS }\end{array}$ & Sudden death at 4 years \\
\hline 18 & 4 months & $\begin{array}{l}\text { OPVD (infracardiac),cAVSD, TGA, } \\
\text { PAt,PDA }\end{array}$ & $\begin{array}{l}\text { OPVD repair } \\
\text { plus SPS }\end{array}$ & $\begin{array}{l}\text { Survivor; } \\
\text { Fontan performed at } \\
\text { the age of } 1.3 \text { years }\end{array}$ \\
\hline 19 & 4 months & VSD,DORV,PAt, PDA & SPS & $\begin{array}{l}\text { Survivor; } \\
\text { Fontan performed at } \\
\text { the age of } 2 \cdot 7 \text { years }\end{array}$ \\
\hline 20 & 6 weeks & $\begin{array}{l}\text { Supracardiac TAPVC,cAVSD, } \\
\text { TGA,PAt,PDA }\end{array}$ & SPS & $\begin{array}{l}\text { Survivor, second SPS } \\
\text { performed } 1 \text { day } \\
\text { postoperatively }\end{array}$ \\
\hline
\end{tabular}

BV, biventricular repair; CA, common atrium; cAVSD, complete atrioventricular septal defect; CP, cavopulmonary; DIRV, double inlet right ventricle, DORV, double outlet right ventricle, OPVD, obstructed pulmonary venous drainage; PA, pulmonary atresia; PAt, pulmonary atresia; PDA, patent ductus arteriosus; PSt, pulmonary stenosis; SPS, systemic pulmonary shunt, TAPVC, total anomalous pulmonary venous connection; TGA, transposition of the great arteries; VSD, ventricular septal defect.

our department over a 6 year period were reviewed to assess whether outcome after surgery is improved.

\section{Patients and methods}

Data of 20 consecutive patients ( 12 boys; M:F ratio $1 \cdot 5: 1$ ) with complex congenital heart disease and right atrial isomerism presenting to our department between August 1987 and July 1993. The age at presentation ranged from 1 day to 2 years (mean $3 \cdot 1$ months). Six ( $30 \%$ ) of the 20 patients were Asian, although the Asian population in the referral area constitutes only $5 \cdot 8 \%$ of the total population. This finding reflects a higher prevalence of complex congenital heart disease in Asian children than in non-Asians. ${ }^{10}$

DIAGNOSIS

The diagnosis of right atrial isomerism was made by cross sectional echocardiography documenting the abnormal juxtaposition of the abdominal aorta and inferior vena cava. ${ }^{11}$ The intracardiac anatomy was defined by a combination of cross sectional imaging and selected Doppler ultrasound studies (table).
Although patients with right atrial isomerism have anomalous pulmonary venous drainage, we separated the patients by describing as "anomalous" only those in whom drainage was not directly to the left sided atrium. The diagnosis was subsequently verified at surgery, cardiac catheterisation or necropsy. The splenic status was verified by abdominal ultrasound and blood films for the presence of Howell-Jolly bodies.

All patients who presented within the first month of life had inadequate pulmonary blood flow and required prostaglandin infusion. Seven patients in this group were found to have obstructed pulmonary venous drainage. The diagnosis was aided by prostaglandin infusion as it unmasked the obstructed pulmonary venous return by augmenting pulmonary blood flow. ${ }^{11}$

SURGERY

All patients were offered and subsequently underwent surgery. A total of 41 surgical procedures were carried out. The age at initial surgical intervention ranged from 1 day to 2 years, with a mean age of $3 \cdot 2$ months. Standard surgical techniques were employed 
Figure 1 Influence of obstructed pulmonary venous drainage (OPVD) on the outcome of surgery in patients with right atrial isomerism requiring initial palliation within the first month of life (group $A$ ). month of life (group $A)$.
$H D$, hospital death; $L D$, late death; $L S$, late survivor; $C P$, cavopulmonary.

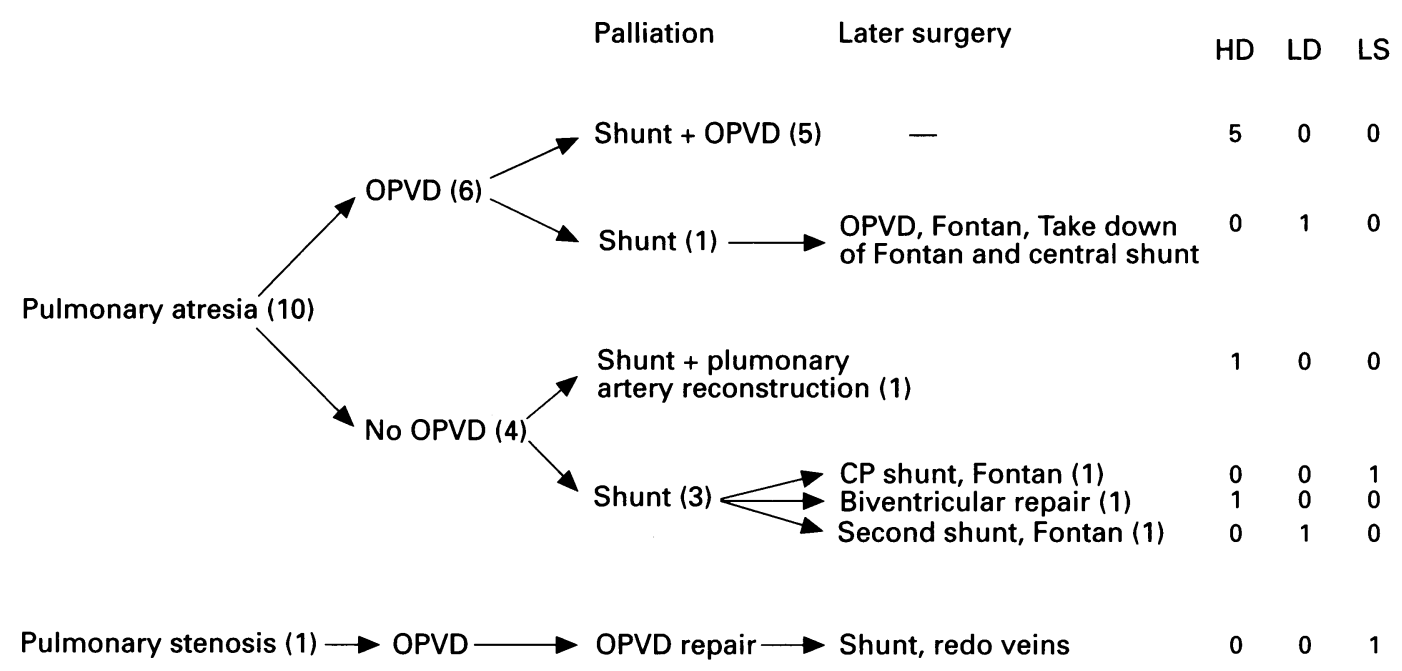

in all patients. Cavopulmonary shunt procedures were carried out using cardiopulmonary bypass. Modifications of the Fontan procedure were used to allow for the complex types of anomalous systemic and pulmonary venous return.

\section{ANALYSIS}

Data of all patients were reviewed and analysed. Patients were divided into two groups depending on age at presentation and initial surgical procedure: group A consisted of 11 infants presenting and requiring surgical intervention within the first month of life; and group B consisted of nine infants and children presenting and requiring surgical intervention after the first month of life.

Hospital death was defined as death within 30 days of operation or during the same hospital admission. Late survivors were reviewed in dedicated follow up clinics. The follow up interval ranged from 1 to 6.8 (mean $3 \cdot 8$ ) years. The $\chi^{2}$ test was used for statistical analysis.

\section{Results}

PATIENTS PRESENTING WITHIN THE FIRST MONTH OF LIFE

Eleven infants (group A) presented at age 1-14 days (mean 5 days). Nine patients had anomalous pulmonary venous drainage, which was obstructed in seven (64\%), four with supracardiac and three with infracardiac drainage. Pulmonary outflow tract obstruction was present in all patients. Ten $(91 \%)$ had pulmonary atresia and one had severe valvar and subvalvar pulmonary stenosis. Ten patients $(91 \%)$ had transposed great arteries, four $(36 \%)$ of these having double outlet of the right ventricle. All patients had a complete atrioventricular septal defect, seven (64\%) having a common atrium.

\section{Obstructed pulmonary venous drainage}

Of the seven patients with obstructed pulmonary venous drainage, five required creation of a systemic to pulmonary artery shunt together with repair of obstructive pulmonary venous drainage (fig 1). All five patients presented within the first week of life and died postoperatively. Before operation two of them deficit of $>5 \mathrm{mmol} / \mathrm{l}$ while taken for surgery. Postoperatively, two (nos 7 and 9) experienced a sudden cardiac arrest within $12 \mathrm{~h}$ of surgery and both were found to have large subarachnoid haemorrhage at necropsy. The other three (nos 2, 3, and 6) experienced postoperative severe cardiac and renal failure. Peritoneal dialysis was complicated by sepsis in two of them.

In one patient (no 4) obstructed pulmonary venous return (infradiaphragmatic) was diagnosed only after the creation of a systemic to pulmonary shunt. Repair of the anomalous pulmonary venous connection was carried out 2 weeks after initial surgery. The patient underwent a modified Fontan operation at the age of 2.5 years, but died in hospital. Postmortem examination documented changes consistent with pulmonary vascular disease.

One patient with pulmonary stenosis (no 10) underwent repair of obstructed pulmonary venous drainage. The patient developed restenosis at 6 months of age, which was relieved surgically. He subsequently underwent a systemic to pulmonary artery shunt operation at 1 year of age for increasing cyanosis but is not considered a candidate for either a Fontan procedure or biventricular repair.

Non-obstructive pulmonary venous drainage sia and non-obstructive pulmonary venous drainage. One of these had discontinuity of the pulmonary arteries and thus needed extensive reconstruction in addition to creation of a systemic to pulmonary artery shunt (no 1). This patient died of low output failure three days postoperatively. Another patient suffered from severe congestive heart failure after creation of a shunt (no 8). Biventricular repair was attempted 12 days later, but the patient died intraoperatively. The third patient underwent systemic to pulmonary artery shunt at 1 week of life and required a second shunt at 4 months of age (no 5). The patient underwent correction of the unobstructed anomalous pulmonary venous connection and a cavopulmonary shunt at the age of 2.5 years. At 5 years completion of a modified Fontan proce- (nos 3 and 6) were ventilated and had a base

There were four patients with pulmonary atre- 
Figure 2 Outcome and management of patients requiring surgery after the first month of life (group first month of life (group
$B$ S Sudden death. $B T$ Blalock-Taussig; CP, cavopulmonary; TAPVC, total anomalous pulmonary venous connection; $H D$, hospital death; $L D$, late death; $L S$, late survivor.

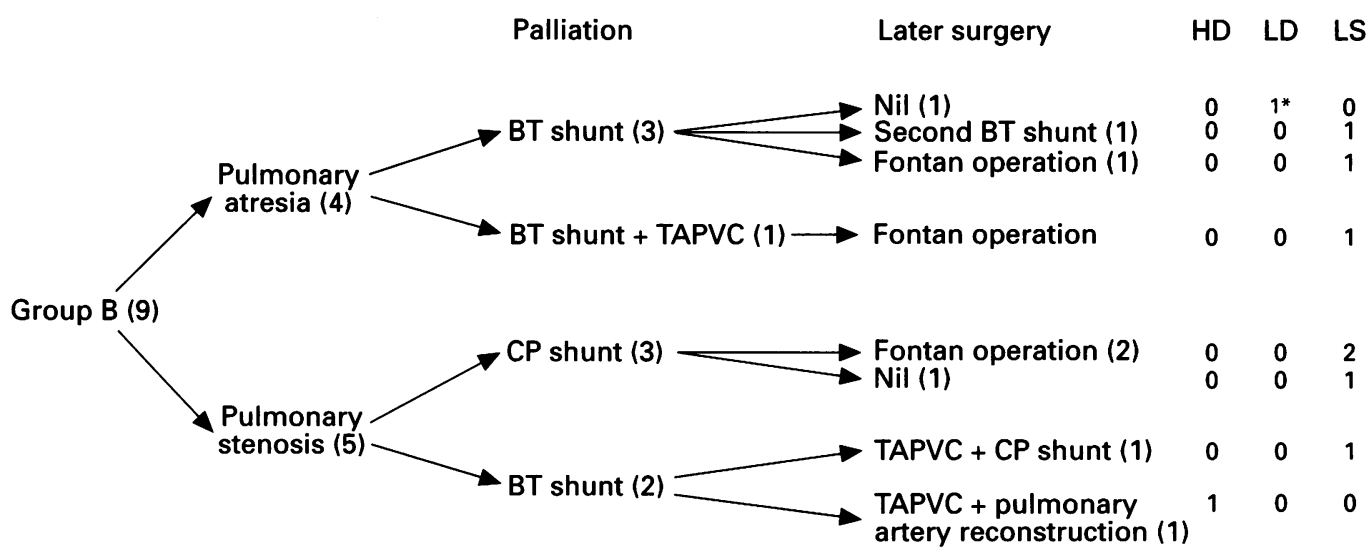

dure was performed and the patient is well and active 1.5 years after operation. The last patient (no 11) required a second modified Blalock-Taussig shunt 1 day after the initial shunt procedure. This patient had a modified Fontan procedure at 4 years of age but died 12 days postoperatively from multiorgan failure and sepsis.

\section{Outcome in group $A$}

In this group as a whole, the hospital mortality during initial surgical palliation was $64 \%$ (seven of 11). There were two hospital deaths after modified Fontan procedures, 2.5 years and 4 years after the initial palliation. Thus, there are only two survivors (two of $11,18 \%$ ) at 1.8 and 6.8 years after initial palliation. One survivor had a successful Fontan procedure, while the other is not judged to be a suitable candidate.

Of the seven patients who presented at less than 1 month of life with obstructed pulmonary venous return there is only one longterm survivor (one of seven, $14 \%$ ).

\section{PATIENTS PRESENTING AFTER THE FIRST MONTH OF LIFE}

In nine patients (group B) initial presentation and surgical intervention occurred after the first month of age (range 5 weeks to 2 years, mean age 6.8 months). Pulmonary venous drainage was anomalous in five patients (supracardiac in three, cardiac in one, and infracardiac in one). This was obstructed in

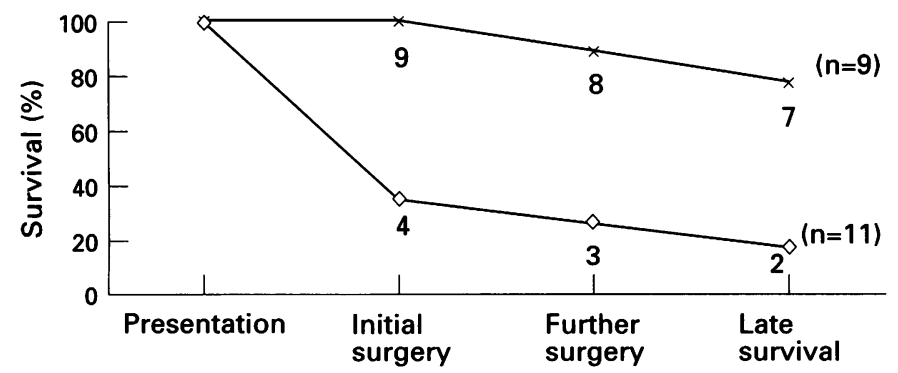

Survival (\%) in patients operation on at

$\begin{array}{llrll}<4 \text { weeks of age }(\diamond) & 100 & 36 & 27 & 18^{*} \\ >4 \text { weeks of age }(\times) & 100 & 100 & 89 & 78\end{array}$

Figure 3 Survival curves for the two subgroups of patients with right atrial isomerism. ${ }^{\star} P<0.001$ versus patients requiring surgery after the first month of life. ( $\chi^{2}$ test). two patients; one with infradiaphragmatic drainage (no 18) and one (no 12) with partially obstructed supracardiac drainage (table). Four patients (44\%) had pulmonary atresia; three with adequate sized persistent arterial duct and one with large major aortopulmonary collateral arteries (no 17). In the remaining five patients, two had valvar pulmonary stenosis while three had valvar and subvalvar pulmonary stenosis. Six patients $(67 \%)$ had transposed great arteries with double outlet of the right ventricle in four (44\%). A complete atrioventricular septal defect was present in eight patients $(89 \%)$, while one had a doubly committed subarterial ventricular septal defect.

The initial surgical procedures performed in this group were systemic to pulmonary artery shunt in five patients, systemic to pulmonary artery shunt together with repair of anomalous pulmonary venous drainage in one, cavopulmonary shunt in two, and cavopulmonary shunt with repair of anomalous pulmonary venous drainage in one. There were no early deaths (fig 2).

Three of the four patients with pulmonary atresia (nos 18, 19, and 20) had a systemic to pulmonary artery shunt between 6 weeks and 4 months of life as the initial surgical procedure. The fourth had ligation of major aortopulmonary collateral arteries (no 17) at 1 year. This patient was well and active, but died suddenly aged 4 years, 2.9 years after the shunt operation. One patient required a second modified Blalock-Taussig shunt during follow up (no 20). This patient has multiple congenital problems and is currently not considered to be a suitable candidate for a Fontan procedure. Another patient (no 19) underwent a successful Fontan operation. The patient who underwent systemic to pulmonary artery shunt together with repair of anomalous pulmonary venous drainage (no 18) underwent a modified Fontan operation at 1.3 years of age. Refashioning of the atrial baffle was required in the early postoperative period because of severe cyanosis but the patient is well and active at $6 \cdot 2$ years of age.

Of the five patients with pulmonary stenosis, one (no 12) had a systemic to pulmonary artery shunt at the age of 5 weeks and required repair of partially obstructive supracardiac anomalous pulmonary venous drainage along 
with division of main pulmonary artery at 6 months of age and died postoperatively. Two patients (nos 13 and 15) had a Fontan operation after a cavopulmonary shunt. Both are well and active 4 and 5 years after their initial palliation. The remaining two patients (nos 14 and 16) are well and stable after bilateral cavopulmonary shunts and are considered good candidates for a modified Fontan operation.

\section{Outcome in group B}

There are seven late survivors $(78 \%)$ in group B (fig 2). Four patients (44\%) had Fontan operations (nos 13,15, 18, and 19) with no hospital or late mortality. All are well at a mean of $3 \cdot 7$ (range $1 \cdot 5-5 \cdot 5$ ) years after the initial operation. Two patients had cavopulmonary shunts (nos 14 and 16) and are suitable for Fontan operation (currently awaiting surgery). One patient (no 20) has multiple other problems including global developmental delay and is considered not to be suitable for a future Fontan procedure.

\section{COMBINED RESULTS}

The overall survival rate in this study population was $45 \%$ (nine of 20 ). The survival rate was $18 \%$ (two of 11 ) in patients requiring surgery in the first month of life (group A) as opposed to $78 \%$ (seven of nine) in those who presented and required surgery after the first month of life (group B) $(\mathbf{P}<0.001)$ (fig 3).

Modified Fontan operations were performed in a total of seven patients with two hospital deaths. Two of the remaining four survivors are candidates for Fontan operations, the other two are not considered to be suitable candidates. Thus, $78 \%$ (seven of nine) of the late survivors and $35 \%$ (seven of 20) of the total study population either have survived a Fontan procedure or are potential candidates. No survivor is suitable for biventricular repair.

\section{Discussion}

Previous studies have reported a poor surgical outcome in patients with complex congenital heart disease and right atrial isomerism. ${ }^{578}$ These studies were limited by small patient populations and limited follow up information. Moreover, in view of the much improved results in infant cardiac surgery over the past decade, one might assume a change in the prognosis of children with these complex lesions in the current era.

\section{DIAGNOSIS}

The diagnosis of right atrial isomerism and documentation of intracardiac anatomy was made by transthoracic ultrasound in all patients. Nine of the eleven patients who required surgery within the first month of life underwent initial palliation without prior cardiac catheterisation or angiocardiography. Prostaglandin was instituted in all patients with inadequate pulmonary blood flow presenting within the first month of life. Prostaglandin augments the pulmonary blood flow in these patients and the potential obstructed pulmonary venous drainage which may remain unnoticed by severe restriction of pulmonary blood flow may therefore be unmasked. ${ }^{12}$ Pulmonary venous obstruction was correctly identified using ultrasound techniques in all but one patient before operation. In this patient, it was diagnosed only after creation of a systemic to pulmonary shunt which led to a marked increase in pulmonary blood flow.

\section{INITIAL PALLIATION}

In five neonates with obstructed pulmonary venous return and pulmonary atresia the initial surgical procedure was correction of the anomalous pulmonary venous connection and creation of a systemic to pulmonary artery shunt. All of these patients died. Di Donato et $a l^{7}$ have previously reported similar results in four patients who were much older. The sizes of the systemic to pulmonary artery shunts in our series were either 3.5 or $4 \mathrm{~mm}$. Postmortem examination documented a patent shunt and wide pulmonary venous anastomosis in the five patients. Causes leading to death were multiorgan failure due to low cardiac output. This was complicated by sepsis in three patients and large subarachnoid haemorrhage in two. No patient in this subgroup of patients was found to suffer from noticeably increased pulmonary blood flow immediately postoperatively. One might speculate that transient increase of pulmonary vascular resistance after cardiopulmonary bypass in these critically ill neonates may have contributed to low cardiac output failure in the early postoperative period. Thus, greater utilisation of techniques to manipulate pulmonary vascular resistance might potentially improve these results.

Poor preoperative status seems to be one of the factors responsible for poor outcome in these patients. Three of these five patients were clinically unstable at presentation with low saturations and acidosis. Although one of them could be stabilised before operation, two were not improved when taken for surgery. It is conceivable that antenatal echocardiographic diagnosis might lead to earlier aggressive preoperative management with improvement in preoperative status. This may have a favourable influence on the surgical results.

The outcome is influenced further by the presence of asplenia, which renders these patients susceptible to infection. In three $(27 \%)$ of 11 deaths in our series as a whole, sepsis had been a significant contributory factor.

The early survival rate was $36 \%$ in the group of patients who required surgical intervention within the first month of life. This has to be judged against the results in other severe conditions of neonatal congenital heart disease such as hypoplastic left heart syndrome. Medium-term survival for hypoplastic left heart syndrome has been reported to be above $70 \%,{ }^{12}{ }^{13}$ and in our own unit is approaching $60 \% .^{14}$ In contrast, all of the patients who 
required initial surgical intervention after the first month of age survived initial palliation.

\section{FURTHER PALLIATION}

Of the eleven early survivors of the study population as a whole, seven underwent a modified Fontan procedure. Two of these patients died in the postoperative period, accounting for a hospital mortality for Fontan operations in this group of patients of $29 \%$ (two of seven). This finding is in contrast to our overall hospital mortality for Fontan procedures of $5.5 \%$ (six of 111 consecutive patients) for the same period and highlights the often borderline haemodynamic and morphological findings in patients with right atrial isomerism who require multiple previous palliative procedures. In a recent study by Michielon et al and colleagues $^{15}$ the hospital mortality for Fontan operations in the presence of anomalous systemic or pulmonary venous connections was reported to be $15 \%$ for patients operated on after 1986 . However, no separate values were given for patients with combined pulmonary and systemic venous abnormalities or for those with right rather than left atrial isomerism. Of the remaining four late survivors, two are not considered to be Fontan candidates because of a combination of multiple congenital abnormalities and adverse haemodynamic variables. The other two patients are awaiting Fontan operation. Thus, only five $(25 \%)$ of the total of 20 patients had a successful Fontan operation and another two $(10 \%)$ are potential candidates. A biventricular repair was unsuccessfully attempted in one patient. Such an approach was not deemed to be feasible in any of the other patients encountered, although this may occasionally be possible in selected children. ${ }^{916}$

\section{IMPLICATIONS}

The finding of an early survival rate of $36 \%$ and a late survival of $18 \%$ in patients with right atrial isomerism who required surgical intervention at less than 1 month of age is dis- couraging. In particular, the subgroup of patients presenting within the first week of life with obstructed pulmonary venous return and pulmonary atresia were found to have a very poor prognosis with no late survival. These findings should influence future counselling and antenatal as well as postnatal management.

1 Putschar WG, Manion WC. Congenital absence of the spleen and associated anomalies. Am f Clin Pathol 1956; 26:429-35.

2 Anderson RH, Macartney FJ, Shinebourne EA, Tynan M, eds. Paediatric cardiology. Edinburgh: Churchill Livingstone, 1987:473-96.

3 Rose V, Izukawa T, Moes KAF. Syndromes of asplenia and polysplenia: a review of cardiac and non-cardiac malformations in 60 cases with special reference to diagnosis and prognosis. Br Heart $\mathcal{f} 1975 ; 37: 840-52$.

4 Fyler DC. Report of the New England regional infant cardiac program. Pediatrics 1980;65(suppl):444-7.

5 Kirklin JW, Barrat-Boyes BG, eds. Cardiac surgery. New York: Churchill Livingstone, 1993:1585-96.

6 Waldman JD, Rosenthal A, Smith AL, Shurin S, Nadas AS. Sepsis and congenital asplenia. $f$ Pediatr 1977; A0:555-9.

7 Di Donato R, de Carlo D, Squitieri C, et al. Palliation of cardiac malformations associated with right atrial isomerism (asplenia syndrome) in infancy. Ann Thorac Surg merism (asple

8 Marcelletti C, Di Donato R, Nijveld A, et al. Right and left atrial isomerism: the cardiac surgeon's view. Ann Thorac Surg 1983;35:400-4.

9 Pacifico AD, Ricchi A, Bargeron LM, Colvin EC, Kirklin JW, Kirklin JK. Corrective repair of complete atrioventricular canal defects and major associated cardiac anomalies. Ann Thorac Surg 1988;46:645-51.

10 Sadiq M, Stümper O, Wright JG, De Giovanni JV, Billingham C, Silove ED. Influence of ethnic origin on the pattern of congenital heart defects in the first year of life. Br Heart f 1995;73:173-6.

11 Huhta JC, Smallhorn JF, Macartney FJ. Two dimensional echocardiographic diagnosis of situs. $\mathrm{Br}$ Heart $\mathcal{f} 1982$; 48:97-108.

12 Freedom RM, Olley PM, Coceani F, Rowe RD. The prostaglandin challenge: test to unmask obstructed total anomalous pulmonary venous connections in asplenia anomalous pulmonary venous con

13 Norwood WI, Jacobs ML, Murphy JD. Fontan procedure for hypoplastic left heart syndrome. Ann Thorac Surg 1992;54:1025-30.

14 Bu'Lock FA, Stümper O, Jagtap R, et al. Surgery for infants with a hypoplastic systemic ventricle and severe outflow obstruction; early results with a new modification of the Norwood procedure. Br Heart f 1995;73:456-61.

15 Michielon G, Gharagozloo F, Julsrud PR, Danielson GK, Puga FJ. Modified Fontan operation in the presence of anomalies of systemic and pulmonary venous connection. Circulation 1993;88(Pt 2):141-8.

16 Kawashima Y, Matsuda H, Naito Y, Yagihara T, Kadoba $\mathrm{K}$, Matsuki $\mathrm{O}$. Biventricular repair of cardiac isomerism with common atrioventricular canal with the aid of an endocardial cushion prosthesis. 7 Thorac Cardiovasc Surg 1993;106:248-54. 